\title{
Hearing Rehabilitation through Bone-Conducted Sound Stimulation: Preliminary Results
}

\author{
Fayez Bahmad Jr $r^{1,3}$ Carolina Costa Cardoso ${ }^{2,3}$ Fernanda Ferreira Caldas ${ }^{2,3}$ \\ Monique Antunes De Souza Chelminski Barreto ${ }^{2}$ Anacléia Melo Da Silva Hilgenberg ${ }^{2}$ \\ Marina Santos Teixeira ${ }^{2}$ Lucieny Silva Martins Serra²
}

${ }^{1}$ Department of Otorhinolaryngology, Faculdade de Ciências da

Saúde, Universidade de Brasília, Brasília, DF, Brazil

2 Secretaria de Saúde do Distrito Federal, Brasília, DF, Brazil

${ }^{3}$ Instituto Brasiliense de Otorrinolaringologia, Brasília, DF, Brazil

Int Arch Otorhinolaryngol 2019;23:12-17.

\begin{abstract}
Address for correspondence Fayez Bahmad Jr., PhD, MD, Departmento de Otorrinolaringologia, Faculdade de Ciências da Saúde, Universidade de Brasília, SMHN QD 02 Bloco C ED Dr Crispim Sala 515, ASA NORTE, Brasilia 70710-149, DF, Brazil (e-mail: fayezbjr@gmail.com).
\end{abstract}

\begin{abstract}
Keywords

- hearing loss

- bone conduction

- tinnitus
\end{abstract}

\section{Introduction}

Most people suffering with hearing losses benefit from conventional hearing aids (HAs), which are devices that help receiving, amplifying and transmitting sounds into the ear canal up to the cochlea. These devices may be placed behind or on the ear, and even inside the auditory canal. However, conventional HAs can obstruct ventilation and worsen infections in individuals affected by inflammatory processes in the ear. In addition, people carrying congenital anomalies, such as aural atresia, do not benefit from conventional HAs, since the anomaly may prevent the proper fixation of the device. ${ }^{1}$

Bone-anchored hearing aids (BAHAs) are indicated whenever the reconstructive surgery or the HAs are insufficient or ineffective in providing satisfactory functional hearing, received

June 11, 2017

accepted after revision

June 20, 2018

published online

October 11, 2018
DOI https://doi.org/

10.1055/s-0038-1670694. ISSN 1809-9777.
Copyright $\odot 2019$ by Thieme Revinter

Publicações Ltda, Rio de Janeiro, Brazil
License terms

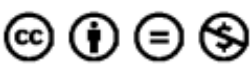


mainly in patients affected by aural atresia, recurrent otitis and external auditory canal stenosis. ${ }^{2}$

In 1996, the Food and Drug Administration (FDA) approved the use of BAHAs in cases of conductive and mixed hearing loss. In 1999, the FDA indications were extended to children $>5$ years old. The device was approved for bilateral implantation in 2001, as well as in cases of unilateral hearing loss in $2002 .^{3}$

The current BAHAs comprise a titanium screw, an abutment and a processor. The device is able to compensate any degree of hearing loss through bone conduction, as well as to improve a limited range of sensorineural hearing losses. The BAHAs are suitable for patients with conductive hearing loss, and quite significant for patients unable to wear conventional HAs. ${ }^{4}$

The BAHA is the only device able to produce clear sound perception, regardless of the external and middle ear function, when the cochlea remains intact. ${ }^{5}$

Hearing loss is a risk factor for tinnitus, ${ }^{6,7}$ although some authors have found no statistically significant relation between tinnitus and different degrees of hearing loss. However, tinnitus is more often found in patients with coexisting hearing loss.

The improved auditory threshold resulting from the use of HAs is associated with a decrease in the severity of the tinnitus. $^{8,9}$

Newman et al (1996) ${ }^{10}$ developed the tinnitus handicap inventory (THI), which was translated into Brazilian Portuguese as Inventário do Handicap do Zumbido and was validated by Ferreira et al $(2005)^{11}$ to measure tinnitus. The inventory comprises 25 questions divided into 3 scales (functional, emotional and catastrophic).

The visual analog scale (VAS), which is widely used to assess chronic pain, is another method used to measure tinnitus symptoms. The method consists of presenting a ruler (scale ranging from 0 to 10 ) to the patient, who should indicate the tinnitus volume intensity and discomfort level. ${ }^{12}$

\section{Objective}

In light of the aforementioned information, the aim of the current study is to analyze the possible audiometry, functional gain, speech perception test, THI and VAS performance variables in a sample comprising hearing-impaired BAHA users.

\section{Methodology}

The project was submitted to the evaluation of the Research Ethics Committee (CEP, in the Portuguese acronym) through Plataforma Brasil (Brazil Platform), opinion number 349628. The patients signed the free and informed consent Form (ICF). They agreed to participate in the research and authorized the use of data resulting from their participation.

\section{Study Population}

\section{Inclusion Criteria}

Patients with postlingual hearing loss, that is, the hearing loss happened after language acquisition with bilateral or unilateral hearing loss.

Patients with idiopathic-origin tinnitus.

Patients referred by the otorhinolaryngologist to bone amplification surgery between 2012 and 2013.

\section{Exclusion Criteria}

Patients who tested the BAHA device, but who did not undergo surgery.

\section{Profile of the Participants.}

The sample comprised 5 BAHA users ( 3 women and 2 men) with hearing loss, in the age group between 36 and 54 years old.

Patient 1 (n1) - Hearing loss: bilateral moderate conductive. Implanted ear: right ear.

Patient 2 (n2) - Hearing loss: bilateral severe mixed. Implanted ear: right ear.

Patient 3 (n3) - Hearing loss: left ear-moderate mixed. Right ear - within the normality pattern. Implanted ear: left ear. Patient 4 (n4) - Hearing loss: left ear - severe mixed. Right ear - moderate mixed. Implanted ear: left ear.

Patient 5 (n5) - Hearing loss: left ear - severe mixed. Right ear - moderate mixed. Implanted ear: left ear (-Table 1).

Table 1 Participants' profile

\begin{tabular}{|l|l|l|l|l|l|}
\hline & Gender & Age & Hearing loss type and degree & Implanted ear & Osteointegration time \\
\hline $\begin{array}{l}\text { Individual 1 } \\
(\mathrm{n} \text { 1) }\end{array}$ & $\mathrm{F}$ & 36 years old & $\begin{array}{l}\text { LE: Moderate conductive } \\
\text { RE: Moderate conductive }\end{array}$ & Right ear & 4 months \\
\hline $\begin{array}{l}\text { Individual 2 } \\
(\mathrm{n} \text { 2) }\end{array}$ & $\mathrm{F}$ & 53 years old & $\begin{array}{l}\text { LE: Severe mixed } \\
\text { RE: Severe mixed }\end{array}$ & Right ear & 4 months \\
\hline $\begin{array}{l}\text { Individual 3 } \\
(\mathrm{n} 3)\end{array}$ & $\mathrm{M}$ & 45 years old & $\begin{array}{l}\text { LE: Severe mixed } \\
\text { RE: Within the normality pattern }\end{array}$ & Left ear & 4 months \\
\hline $\begin{array}{l}\text { Individual 4 } \\
(\mathrm{n} 4)\end{array}$ & $\mathrm{F}$ & 54 years old & $\begin{array}{l}\text { LE: Severe mixed } \\
\text { RE: Moderate mixed }\end{array}$ & Left ear & 4 months \\
\hline $\begin{array}{l}\text { Individual 5 } \\
(\mathrm{n} 5)\end{array}$ & $\mathrm{M}$ & 48 years old & $\begin{array}{l}\text { LE: Severe mixed } \\
\text { RE: Moderate mixed }\end{array}$ & Left ear & 4 months \\
\hline
\end{tabular}




\section{Tests and Exams}

Free-field Tone Audiometry before Surgery

The free-field tone audiometry was performed at the frequencies of $500,1,000,2,000,3,000$, and $4,000 \mathrm{~Hz}$. The narrowband noise masking was performed through the air conduction of sounds to the contralateral ear, whenever necessary.

\section{Functional Gain Audiometry 6 Months after Device Activation}

The auditory improvement was calculated by subtracting the free-field airborne auditory thresholds by the functional gain thresholds in all the tested frequencies. The functional gain was defined as the difference (in decibels [dB]) between the free-field auditory thresholds, with and without the device, under the same test conditions.

\section{Speech Perception Test under Silence Condition before} and after Device Activation

The list of sentences-Audiological Research Center (CPA, in the Portuguese acronym)-proposed by Valente $(1998)^{13}$ was used in the current study. The sentences were distributed by keeping a constant 10 -second interval between the end of a sentence and the beginning of the next one. All audiological and speech perception assessment procedures were performed in an acoustic booth. The list of monosyllables and disyllables proposed by Lacerda $(1976)^{14}$ was used in the present study.

The THI and VAS was applied in open format before and after surgery.

\section{Statistical Analysis}

The database was prepared in Excel format. The non-parametric Wilcoxon test was used to compare the different measures before and after the BAHAs were implanted. Differences presenting $p$-values $<0.05$ were considered significant. The statistical analysis was conducted in SPSS Statistics for Windows, Version 20.0 (IBM Corp, Armonk NY, USA).

\section{Results}

The results were didactically divided in four groups-sample characterization, audiological results, speech perception test results, and tinnitus assessment results-in order to be better analyzed.

\section{Audiological Results}

The median auditory threshold values found at frequencies ranging from 500 to $4,000 \mathrm{~Hz}$ after the implantation were significantly lower than the values found before the implantation ( $p=0.031$, in all comparisons).

The frequency of $3,000 \mathrm{~Hz}$ showed the highest free-field audiological threshold variation in all individuals. - Fig. 1 shows the results of the functional gain audiometry at frequencies ranging from 500 to $4,000 \mathrm{~Hz}$.

\section{Speech Perception Tests}

The speech perception tests showed no significant difference in the correct-answer median values concerning disyllables, monosyllables, and sentences after the implantation, in comparison to the median values before the implantation ( $p=0.063$, in all comparisons), although they showed an improved rate of correct answers. =Figs. 2, 3 and $\mathbf{4}$ show the results of the speech perception tests using monosyllables, disyllables, and sentences.

\section{Tinnitus Results}

The analysis of the number of patients in each THI category showed 3 patients presenting mild hearing loss (60\%), 1 with moderate hearing loss (20\%), and 1 with severe hearing loss (20\%) before the implantation. On the other hand, 4 patients showed slight hearing loss (80\%), and 1 presented mild hearing loss (20\%) after the implantation.

The bar graph depicts the qualitative improvement in preexisting tinnitus after the surgery, according to the changes in the THI scale. There was no significant difference in the median THI value before and after implantation $(p=0.063)$. - Table 2 shows the THI category classification.

The analysis of the number of patients in each VAS category showed 2 patients in the mild category (40\%), and 3 in the severe category (60\%) before the implantation. On the other hand, 4 patients were in the mild category (80\%), and 1 was in the moderate category (20\%) after the implantation. - Table 3 shows the VAS category classification.

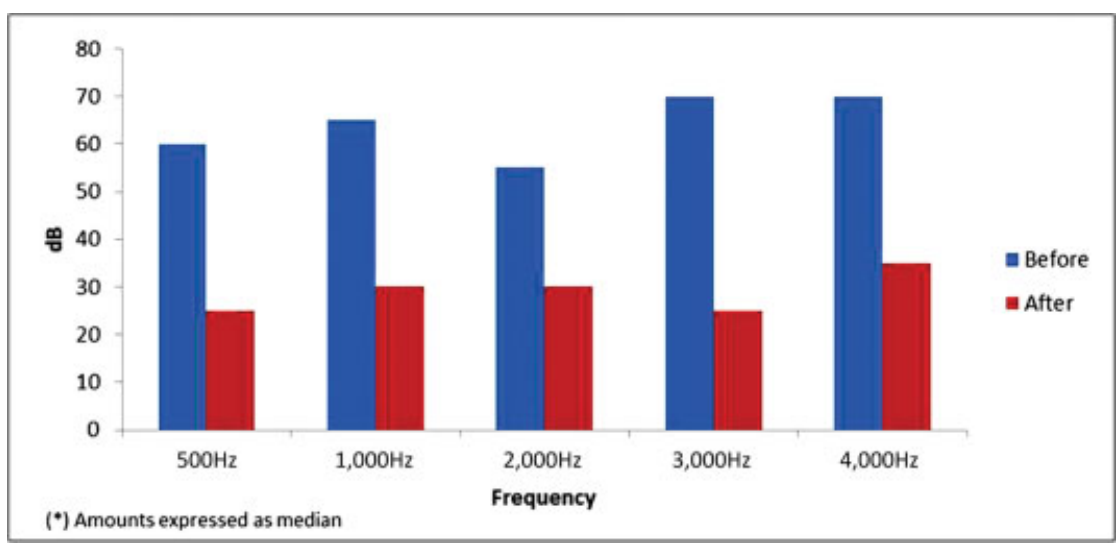

Fig. 1 Functional gain audiometry at frequencies ranging from $500 \mathrm{~Hz}$ to $4,000 \mathrm{~Hz}$. 


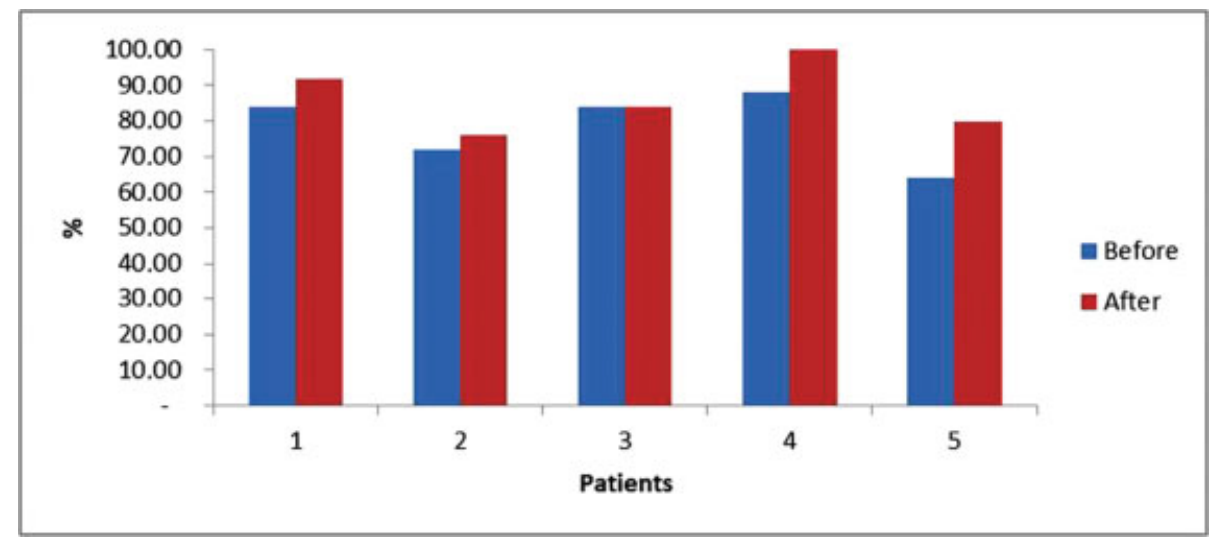

Fig. 2 Speech perception tests using monosyllables.

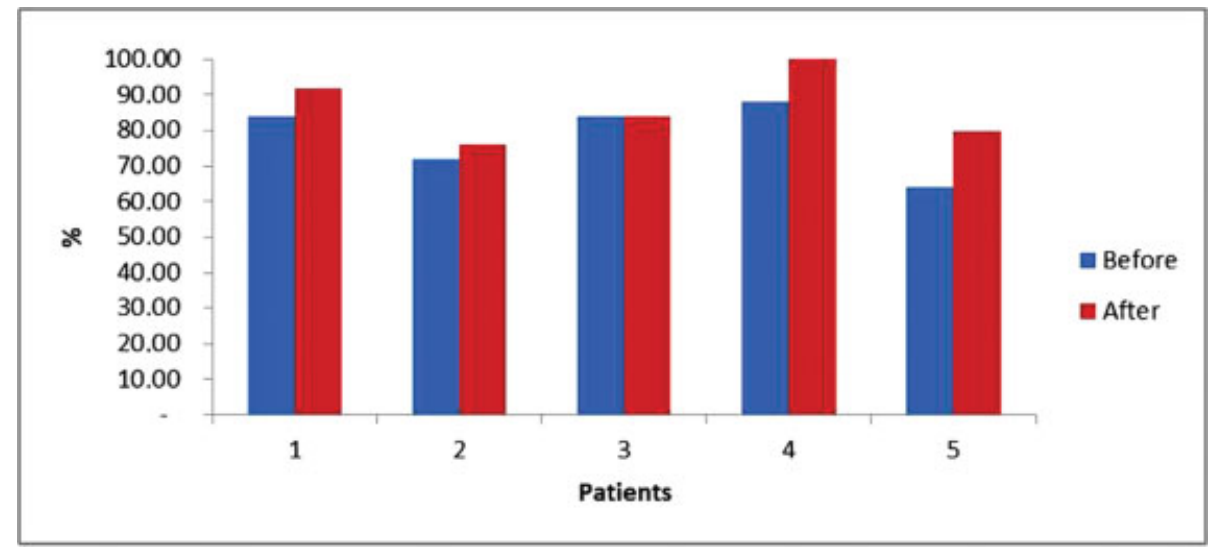

Fig. 3 Speech perception tests using disyllables.

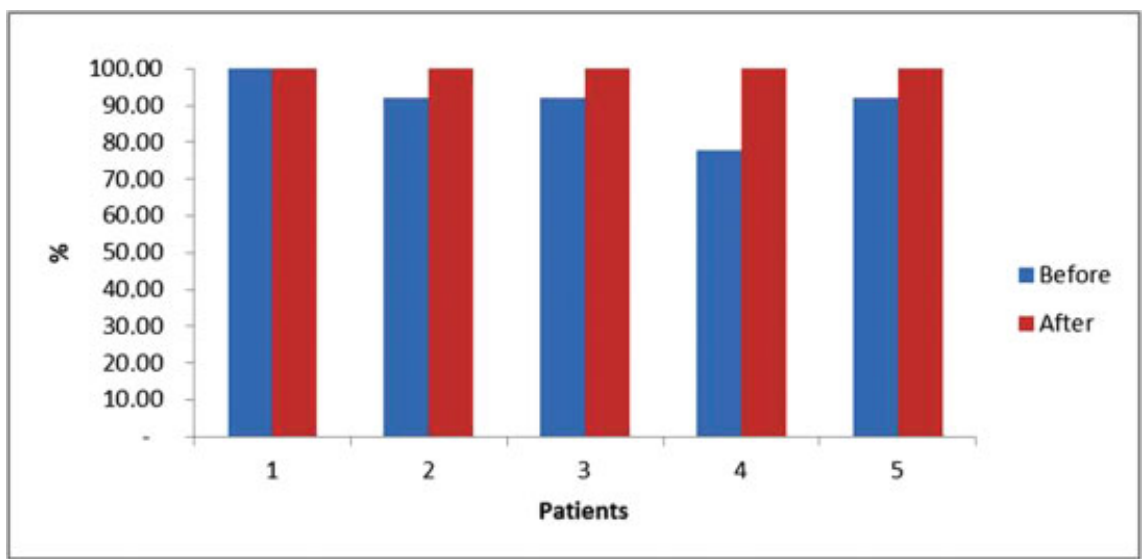

Fig. 4 Speech perception tests using sentences.

The bar graph shows the qualitative improvement in the preexisting tinnitus after the surgery, according to the changes in the VAS scale. The median VAS intensity and discomfort values after the implantation were significantly lower than the values found before the implantation $(p=0.031)$. - Figs. 5 and $\mathbf{6}$ show the VAS category classification of intensity and discomfort.

\section{Discussion}

The aim of the present study was to investigate the benefit to and the satisfaction of patients with conductive, mixed, and sensorineural hearing loss with the BAHA device. This investigation was conducted through the application of auditory tests and instruments used to assess tinnitus. 
Table 2 THI category classification

\begin{tabular}{|c|c|c|c|c|c|}
\hline \multirow{2}{*}{$\begin{array}{l}\text { THI } \\
\text { Before }\end{array}$} & \multicolumn{4}{|l|}{ After } & \multirow[b]{2}{*}{$\begin{array}{l}\text { Total } \\
\text { before } \\
\text { (\%) }\end{array}$} \\
\hline & Slight & Mild & Moderate & Severe & \\
\hline Slight & & & & & $0(0.0)$ \\
\hline Mild & 2 & 1 & & & $3(60.0)$ \\
\hline Moderate & 1 & & & & $1(20.0)$ \\
\hline Severe & 1 & & & & $1(20.0)$ \\
\hline $\begin{array}{l}\text { Total } \\
\text { after (\%) }\end{array}$ & $\begin{array}{l}4 \\
(80.0)\end{array}$ & $\begin{array}{l}1 \\
(20.0)\end{array}$ & $\begin{array}{l}0 \\
(0.0)\end{array}$ & $\begin{array}{l}0 \\
(0.0)\end{array}$ & $\begin{array}{l}5 \\
(100.0)\end{array}$ \\
\hline
\end{tabular}

Abbreviations: THI, tinnitus handicap inventory.

Table 3 VAS category classification

\begin{tabular}{|c|c|c|c|c|}
\hline \multirow{2}{*}{$\begin{array}{l}\text { VAS - discomfort } \\
\text { and intensity } \\
\text { Before }\end{array}$} & \multicolumn{3}{|l|}{ After } & \multirow[b]{2}{*}{$\begin{array}{l}\text { Total } \\
\text { before } \\
\text { (\%) }\end{array}$} \\
\hline & Mild & Moderate & Severe & \\
\hline Mild & 2 & 0 & 0 & $2(40.0)$ \\
\hline Moderate & 0 & 0 & 0 & $0(0.0)$ \\
\hline Severe & 2 & 1 & 0 & $3(60.0)$ \\
\hline Total after (\%) & $4(80.0)$ & $1(20.0)$ & 0 & $5(100.0)$ \\
\hline
\end{tabular}

Abbreviations: VAS, visual analog scale.

According to the postsurgery results, the BAHA device provided a significant auditory improvement, which was confirmed through the audiometric measurements. In addition, it enabled functional gain and suppressed tinnitus.

The five participants subjected to the frequencies investigated in the present study showed a significant improvement during the free-field functional gain audiometry. These results corroborate the study by Boleas-Aguirre et al $(2012),{ }^{15}$ who investigated the frequencies of $500,1,000$, 2,000 , and $3,000 \mathrm{~Hz}$ in the free-field and found mean value gains of $22,33,20$, and $15 \mathrm{~dB}$, respectively. They also corroborate the findings by Byrne et al (1994), ${ }^{16}$ who found an auditory improvement from 5 to $15 \mathrm{~dB}$ in patients subjected to the investigation of the frequencies of $500,1,000$, 2,000, 3,000, and 4,000 Hz.

Studies comprising patients with aural atresia, chronic otitis media, otosclerosis and chronic external otitis showed evident hearing improvement after the implantation of BAHAs. Lustig et al $(2001)^{17}$ reported pure tones of $\sim 28 \mathrm{~dB}$ and a hearing gain of $33 \mathrm{~dB}$, on average. Liepert et al $(1994)^{18}$ reported a similar mean hearing gain $(30 \mathrm{~dB})$ at the speech reception threshold (SRT), whereas Wazen et al $(1998)^{19}$ found SRT improvement.

The patients subjected to speech perception tests in the present study showed gains. However, these gains were not as significant as those reported by Flynn (2012), ${ }^{20}$ who recorded lower, but non-significant $(F[1,19]=1.83, p>0.05)$ speech

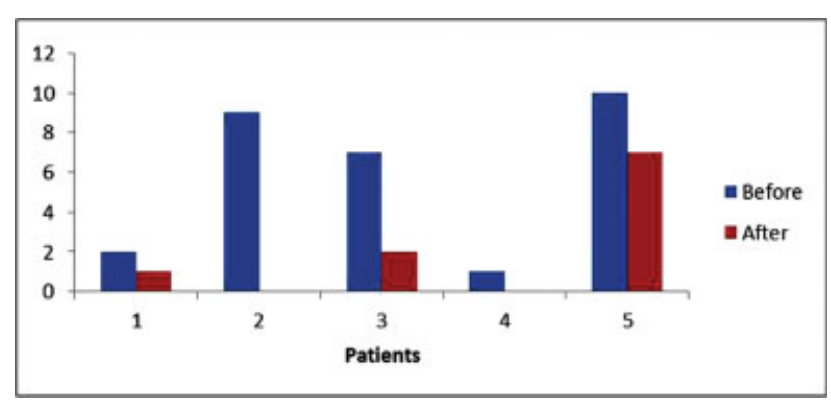

Fig. 5 VAS category classification - intensity.

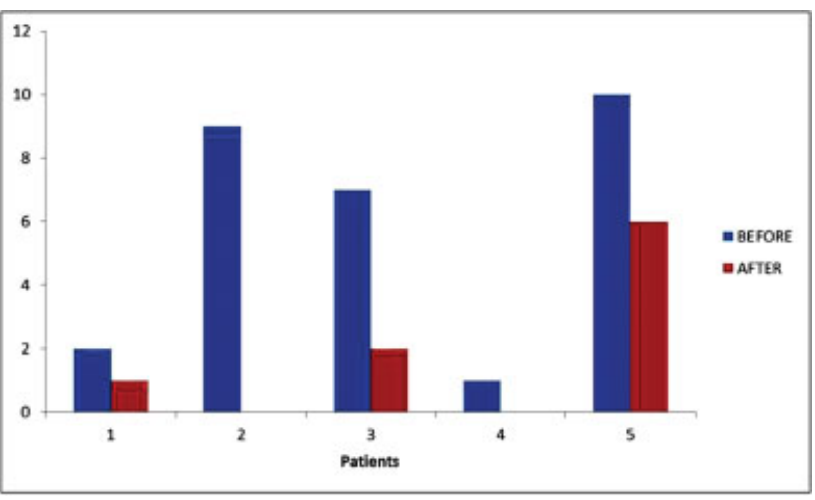

Fig. 6 VAS category classification - discomfort.

recognition under silence condition (4-5\%). Therefore, they found $50 \mathrm{~dB}$ and $65 \mathrm{~dB}$ improvement in the test-sound processor.

Some studies suggest that the bone conduction transmission is useful in cases of unilateral sensorineural hearing losses because it helps overcoming some of the limitations associated with severe and deep hearing loss. ${ }^{21,22}$ In addition, it helps improving the satisfaction of the users, ${ }^{23}$ although there is some controversy in cases of unilateral sensorineural losses ${ }^{24}$

The benefits achieved by patients with mixed hearing loss were more significant in the present study, since these patients presented bilateral air and bone conduction impairment. Mylanus et al (1998) ${ }^{25}$ compared the audiometric results BAHAs and HAs and concluded that the larger the bone-air gap, the greater the benefit from BAHAs in comparison to that from HAs.

The use of BAHAs by patients with unilateral conductive or mixed hearing loss was a successful method in the present study, since the normal contralateral hearing increased the chance of the patients to benefit from binaural hearing. Individuals affected by tinnitus can also benefit from BAHAs. $^{26}$

According to the results of the VAS applied in the current study to measure the discomfort and intensity of tinnitus before the implantation of BAHAs, 2 patients were in the mild category (40\%), 2 were in the moderate category (40\%) and 1 was in the severe category (20\%). After the implantation, 4 patients upgraded to the mild category $(80 \%)$, and 1 upgraded to the moderate category (20\%). 
Sánchez (2007) ${ }^{26}$ conducted a study about the improvements in the quality of life of the patients and found that $20.8 \%$ out of $37.5 \%$ of the patients affected by tinnitus before the surgery remained affected by it after the surgery. This difference was statistically significant (37.5 and 20.8\%, $p<0.05$ ); however, their study assessed the presence of symptoms rather than the classification categories.

The aforementioned findings are positively related to data provided by Holgers et al (2002), ${ }^{27}$ who assessed the use of the BAHA device based on a therapy applied to tinnitus patients and recorded 8 patients (with different degrees of tinnitus) benefiting from the bone anchored stimulator. Holgers et al also assessed the tinnitus frequency of the patients, as well as the minimum level of decibels necessary to mask tinnitus through air and bone conduction. In addition, they subjectively assessed the hearing improvements resulting from the bone anchored stimulator. The researchers concluded that the sound transmitted through bone conduction had the same potential to mask tinnitus as the sound transmitted through air conduction in patients with conductive or mixed hearing losses. Thus, their results indicate that a sound generator connected to a BAHA device may favor patients affected by tinnitus.

Studies about improvements in the tinnitus condition due to the use of BAHAs are scarce in the literature. Therefore, it is necessary to conduct further researches using a larger sample to corroborate the current findings.

Based on the tests applied in the current study, it is possible to suggest that the auditory rehabilitation provided by the use of BAHAs is an effective treatment option even for individuals affected by different degrees and types of hearing losses.

\section{Conclusion}

Bone anchored hearing aids have significantly improved the tonal thresholds. They were effective, although not statistically significant, in the speech perception of monosyllables, dissyllables and sentences. In addition, they showed no significant difference in tinnitus reduction; however, they showed upgrades in the classification categories intensity and discomfort classification according to the VAS scale

\section{References}

1 National Deaf Children's Society (NDCS). Quality standards in bone anchored hearing aids for children and young people. London: NDCS; 2003

2 Håkansson B, Tjellström A, Rosenhall U. Hearing thresholds with direct bone conduction versus conventional bone conduction. Scand Audiol 1984;13(01):3-13

3 Koch DB, Staller S, Jaax K, Martin E. Bioengineering solutions for hearing loss and related disorders. Otolaryngol Clin North Am 2005;38(02):255-272

4 Baguley DM, Bird J, Humphriss RL, Prevost AT. The evidence base for the application of contralateral bone anchored hearing aids in acquired unilateral sensorineural hearing loss in adults. Clin Otolaryngol 2006;31(01):6-14
5 Stenfelt S, Goode RL. Bone-conducted sound: physiological and clinical aspects. Otol Neurotol 2005;26(06):1245-1261

6 Ahmad N, Seidman M. Tinnitus in the older adult: epidemiology, pathophysiology and treatment options. Drugs Aging 2004;21 (05):297-305

7 Axelsson A, Ringdahl A. Tinnitus-a study of its prevalence and characteristics. Br J Audiol 1989;23(01):53-62

8 Trotter MI, Donaldson I. Hearing aids and tinnitus therapy: a 25year experience. J Laryngol Otol 2008;122(10):1052-1056

9 Folmer RL, Carroll JR. Long-term effectiveness of ear-level devices for tinnitus. Otolaryngol Head Neck Surg 2006;134(01):132-137

10 Newman CW, Jacobson GP, Spitzer JB. Development of the Tinnitus Handicap Inventory. Arch Otolaryngol Head Neck Surg 1996; 122(02):143-148

11 Ferreira PEA, Cunha F, Onishi ET, Branco-Barreiro FCA, Ganança FF. [Tinnitus Handicap Inventory: cross-cultural adaptation to Brazilian Portuguese]. Pro Fono 2005;17(03):303-310

12 Azevedo AA, Mello PO, Siqueira AG, Figueiredo RR. Análise Crítica dos Métodos de Mensuração do zumbido. Rev Bras Otorrinolaringol 2007;73:418-423

13 Valente SLO. Elaboração de listas de sentenças construídas na língua portuguesa [Tese]. São Paulo: Pontifícia Universidade Católica; 1998

14 LACERDA. A. P. Audiologia clínica. Rio de Janeiro: Guanabara Koogan; 1976:199

15 Boleas-Aguirre MS, Bulnes Plano MD, de Erenchun Lasa IR, Ibáñez Beroiz B. Audiological and subjective benefit results in boneanchored hearing device users. Otol Neurotol 2012;33(04):494-503

16 Byrne D, Dillon H, Tran K, et al. An international comparison of long-term average speech spectra. J Acoust Soc Am 1994; 96:2108-2120

17 Lustig LR, Arts HA, Brackmann DE, et al. Hearing rehabilitation using the BAHA bone-anchored hearing aid: results in 40 patients. Otol Neurotol 2001;22(03):328-334

18 Liepert DR, DiToppa JC. The Nobelpharma auditory system boneanchored hearing aid: the Edmonton experience. J Otolaryngol 1994;23(06):411-418

19 Wazen JJ, Caruso M, Tjellstrom A. Long-term results with the titanium bone-anchored hearing aid: the U.S. experience. Am J Otol 1998;19(06):737-741

20 Flynn MC, Hedin A, Halvarsson G, Good T, Sadeghi A. Hearing performance benefits of a programmable power baha ${ }^{\circledR}$ sound processor with a directional microphone for patients with a mixed hearing loss. Clin Exp Otorhinolaryngol 2012;5(Suppl 1):S76-S81

21 Gluth MB, Eager KM, Eikelboom RH, Atlas MD. Long-term benefit perception, complications, and device malfunction rate of boneanchored hearing aid implantation for profound unilateral sensorineural hearing loss. Otol Neurotol 2010;31(09):1427-1434

22 Saroul N, Akkari M, Pavier Y, Gilain L, Mom T. Long-term benefit and sound localization in patients with single-sided deafness rehabilitated with an osseointegrated bone-conduction device. Otol Neurotol 2013;34(01):111-114

23 House JW, Kutz JW Jr, Chung J, Fisher LM. Bone-anchored hearing aid subjective benefit for unilateral deafness. Laryngoscope 2010; 120(03):601-607

24 Martin TP, Lowther R, Cooper H, et al. The bone-anchored hearing aid in the rehabilitation of single-sided deafness: experience with 58 patients. Clin Otolaryngol 2010;35(04):284-290

25 Mylanus EA, van der Pouw KC, Snik AF, Cremers CW. Intraindividual comparison of the bone-anchored hearing aid and airconduction hearing aids. Arch Otolaryngol Head Neck Surg 1998; 124(03):271-276

26 Sánchez-Camón I, Lassaletta L, Castro A, Gavilán J. Calidad de vida de los pacientes con BAHA. Acta Otorrinolaringol Esp 2007;58 (07):316-320

27 Holgers KM, Håkansson BE. Sound stimulation via bone conduction for tinnitus relief: a pilot study. Int J Audiol 2002;41(05): 293-300 